\title{
REDES DE CONHECIMENTO COMO ESTRATÉGIA DE INOVACÁO NA INDUSTRIAL ALIMENTICIA: um estudo de caso na Danilla Foods
}

\section{KNOWLEDGE NETWORKS AS AN INNOVATION STRATEGY IN THE FOOD INDUSTRIAL:}

\author{
a case study at Danilla Foods
}

\author{
Carlos Francisco Bitencourt Jorge ${ }^{1}$ \\ Marta Lígia Pomim Valentim² \\ Michael J. D. Sutton ${ }^{3}$
}

\begin{abstract}
RESUMO
Identificar se as redes de conhecimento podem proporcionar um melhor aproveitamento das informações e conhecimentos enquanto recursos organizacionais. Dessa forma, as organizações devem considerar o processo de mapear fontes e fluxos informacionais na construção de novos conhecimentos, e como consequência, construir de maneira estruturada as suas redes de conhecimento. Nesse sentido, as indústrias estão submersas em grandes volumes de informações e conhecimentos, porém, não possuem a cultura da valorização destes recursos. Desse modo, torna-se importante considerar os sujeitos que compõe essas organizações, bem como as suas relações nos processos que envolvam o conhecimento e informações. 0 universo da pesquisa foi a Danilla Foods, uma indústria que possui como essência de seu negócio a construção de novos produtos por meio de inovações, uma vez que sua manufatura é realizada por uma empresa terceirizada. Para tanto, foi utilizado o método 'estudo de caso', e com isso aplicou-se em toda a organização um roteiro estruturado de observação direta, questionários fechados e entrevistas estruturadas. Com os dados coletados foi possível realizar uma análise e perceber como os sujeitos organizacionais acessam informações e conhecimentos no ambiente interno e externo. Dessa maneira, foi possível construir a rede de conhecimento da organização, identificando aspectos pontuais para a inovação enquanto processo. Identificou-se que a rede é centralizada em poucos indivíduos, o que pode comprometer a construção de novos conhecimentos. Ao final, foram apresentados parâmetros com o intuito de proporcionar um melhor aproveitamento da indústria em prol de suas inovações via construção de novos conhecimentos.
\end{abstract}

Palavras-Chave: Redes de Conhecimento. Conhecimento. Informação. Inovação. Indústria.

\begin{abstract}
Identify whether knowledge networks can provide a better use of information and knowledge as organizational resources. Thus, organizations must consider the process of mapping sources and informational flows in the construction of new knowledge, and consequently, build their knowledge networks in a structured way. In this sense, industries are immersed in large volumes of information and knowledge, however, they do not have a culture of valuing these resources. Thus, it is important to consider the subjects that make up these organizations, as well as their relationships in the processes that involve knowledge and information. The research universe was Danilla Foods, an industry that has as its essence the construction of new products through innovations, since an outsourced company carries out its manufacture. For this, the 'case study' method was used, and with this, a structured script for direct observation, closed questionnaires and structured interviews was applied throughout the organization. With the data collected, it was possible to carry out an analysis and understand how the organizational subjects access information and knowledge in the internal and external environment. In this way, it was possible to build the organization's knowledge network, identifying specific aspects for innovation as a process. It was identified that the network is centralized in a few individuals, which can compromise the construction of new knowledge. At the end, parameters were presented in order to provide a better use of the industry in favor of its innovations through the construction of new knowledge. Key words: Knowledge Networks. Knowledge. Information. Innovation. Industry.
\end{abstract}

Artigo submetido em 01/05/2020 e aceito para publicação em 03/06/2020

1 Professor na Universidade de Marília (Unimar), Brasil. ORCID_https://orcid.org/0000-0002-5338-1498. E-mail: bitencourt@ gmail.com

2 Professora no Programa de Pós-Graduação em Ciência da Informação. Universidade Estadual Julio de Mesquita Filho, Brasil. ORCID https://orcid.org/0000-0003-4248-5934. E-mail: valentim@valentim.pro.br

3 Ph.D. Escola de Estudos da Informação da Universidade McGill. Anaheim University, Estados Unidos. ORCID https://orcid.org/00000002-6946-5047. E-mail: michaeljdsutton@gmail.com 


\section{INTRODUÇÃo}

Ao realizarem os seus processos organizacionais, as organizações interagem de maneira contínua com informações e conhecimentos. Esses elementos estão inseridos em todos os seus processos, de modo direto ou indireto. Dessa maneira, evidencia-se a importância do processo de identificação das fontes de informações e conhecimentos.

Considerando 0 ambiente interno organizacional, bem como o mercado em que atua, a informação pode ser um elemento chave, sendo capaz de fazer a diferença em diversos momentos e situações, entretanto, muitas vezes não é percebida por quem executa as atividades nas organizações. Nesse sentido a informação passa a ser essencial no estabelecimento de diferenciais competitivos no contexto organizaçional.

As informações são capazes de apoiar o processo decisório, influenciar o comportamento das pessoas, atuar como vetor importantíssimo, multiplicando a sinergia dos esforços ou anulando 0 resultado obtido pelo conjunto, bem como atuam como insumo na construção de novos conhecimentos (MORAES; FADEL, 2007; JORGE, 2017).

Observa-se que as informações são insumos para novos conhecimentos no contexto das organizações e estes quando registrados passam a ser informações, tornando assim a relação e limitação entre esses recursos uma tarefa complexa. Todavia, as organizações utilizam as informações e conhecimentos todo o tempo, e muitas vezes de maneira inconsciente e com isso, a identificação, mapeamento e monitoramento das fontes e fluxos tornam-se essenciais para que ocorra o melhor aproveitamento desses recursos (CH00, 2003; JORGE; VALENTIM, 2016).

Observando 0 exposto, compreende-se que as organizações devem considerar as suas redes de conhecimentos e com isso, obter um melhor aproveitamento da informação e do conhecimento enquanto recursos gerados no ambiente interno e externo da organização. Mediante isso, a presente pesquisa tem como objetivo destacar a importância do mapeamento das fontes e fluxos de informação e conhecimento, e consequentemente, a construção de redes como estratégia voltada para a inovação no contexto das organizações industriais.

Parte-se do pressuposto que a rede de conhecimento quando construída pode atuar como importante ferramenta estratégica capaz de apoiar as organizações em pro/de um melhor aproveitamento desses recursos. Nesse sentido, a presente pesquisa considerou o contexto das indústrias que possuem como base de suas atividades o processo de inovação. 
Diante disso, a pesquisa foi realizada na Danilla Foods, indústria do segmento de doces, possuindo como foco de suas atividades a construção e inovação em produtos, e em sua estrutura 0 processo de manufatura é terceirizado. Nesse sentido, aplicou-se o método ‘Estudo de Caso’, realizando assim a triangulação de dados.

Foram utilizados como instrumentos de pesquisa os dados e informações coletadas por meio da observação direta, questionário fechado e entrevistas semiestruturadas, com o objetivo de que a coleta abrangesse todos os níveis da organização. Ao analisar as informações da organização supracitada, foi possível compreender a dinâmica de sua rede, bem como a relação com a inovação.

Dessa maneira, a rede de conhecimento da Danilla Food foi tangibilizada no formato de sociograma, onde foram identificadas as fontes e fluxos informacionais e de conhecimento dos ambientes interno e externo. Com isso foi possível compreender o comportamento da rede e o seu impacto no processo de inovação na indústria analisada.

\section{REDES DE CONHECIMENTO E AS SUAS CARACTERÍSTICAS NO CONTEXTO ORGA- NIZACIONAL}

Compreender a estrutura e a importância das redes de conhecimento no contexto organizacional passa a ser fundamental para entender o seu impacto nas organizações. Para tanto, a presente pesquisa compreende a rede como um tipo de artifício social em que as relações representam o conhecimento compartilhado entre os participantes (AL-HASHEM; SHAQRAH, 2012).

Dessa forma, as redes permitem que os participantes compartilhem conhecimento em diferentes níveis (SEDIGHI et al., 2018). Naudé et al (2009) complementam ao afirmar que as redes potencializam as relações e construções no contexto das organizações, possibilitando assim uma maior consistência organizacional. Xu, Li e Zeng (2017) mencionam que os recursos estruturais de uma rede indicam a extensão de oportunidades combinatórias de elementos que impactam na motivação de uma empresa em explorar novos conhecimentos.

Com isso, a rede proporciona redução de processos, de formalidade e facilita 0 aumento e combinação de conhecimentos internos e externos capazes de gerar inovações em formatos de produtos ou serviços. Nesse sentido, além de compreender a rede de conhecimento interno, torna-se necessário conhecer as fontes de conhecimentos externos que vão desde as necessidades dos clientes, tendências tecnológicas e sociais. 
Essa ideia é reforçada por Dong e Yang (2015) ao destacar a importância da rede de conhecimento considerando as relações proporcionadas pelo ambiente externo. Os autores apontam que as indústrias ao se relacionarem com outras empresas proporcionam aprendizagem organizacional, cujo processo ocorre por meio dos fluxos de conhecimento de maneira informal.

Dessa maneira, os gestores devem estar mais atentos aos movimentos existentes nas redes de conhecimento de sua organização (LANE et al., 2006; GEBAUER; WORCH; TRUFFER, 2012). Por exemplo, o conhecimento básico e as redes podem contribuir ou evoluir para o ecossistema de negócios por meio de transbordamentos de criadores de conhecimento (por exemplo, universidades, institutos de pesquisa, laboratórios nacionais) a atores de negócios (por exemplo, empresas, distribuidores, clientes) ( $\mathrm{OH}$ et al., 2016).

Com isso observa-se que a rede de conhecimento possui duas dimensões dentro das organizações, ou seja, as redes construídas entre os sujeitos que compõem o ambiente interno e as relações construídas entre estes com outras organizações, governos e outros sujeitos que de alguma maneira se relacionam com a organização. Com isso é possivel compreender que essas redes são independentes, porém complementares no contexto da construção do conhecimento organizacional.

É necessário compreender que essas relações só são possíveis via fluxos informacionais e de conhecimentos sendo estes construídos nas relações entre as fontes. Ao analisarmos uma organização, encontramos três níveis de fluxos informacionais: 0 fluxo da estrutura física (organograma), a estrutura de recursos humanos (capital intelectual) e a estrutura informacional (dados, informações e conhecimentos) (VALENTIM, 2002). Destaque-se que esses fluxos atuam sinergicamente, sendo difícil identificar seus limites, todavia ocorrem dentro do processo de comunicação organizacional, seja esta formal ou informal.

Os fluxos informais atuam diretamente com os conhecimentos gerados pelos sujeitos organizacionais e perpassam todos os níveis operacional, tático e estratégico. Enquanto isso, os fluxos informais atuam com os recursos intangíveis no ambiente organizacional, qual seja, os conhecimentos. Destaque-se que a dificuldade de torná-lo tangível torna-se um grande desafio, afinal, a falta de percepção dos sujeitos organizacionais sobre a importância deste recurso prejudica o seu pleno aproveitamento.

Evidencie-se que as inter-relações dos sujeitos organizacionais e os componentes do ambiente externo constituem os fluxos e estes somados constroem as redes, as quais são constituídas pelos fluxos, nós e densidade. 
Os nós das redes representam as relações que ocorrem entre os sujeitos no ambiente interno e entre os sujeitos e componentes do ambiente externo. Enquanto isso, a densidade consiste na frequência de acesso e relações entre indivíduos e componentes, sendo estes no ambiente interno ou externo.

Cabe à organização desenvolver estratégias que possibilitem 0 aumento da conectividade, e com isso, aumenta-se o conhecimento. A consequência dessas possíveis estratégias é uma rede densa, capaz de buscar novos conhecimentos além do limite organizacional (HANSEN; MORS; LøVÅS 2005).

As relações densas entre os sujeitos (nós das redes) apontam para a construção de conhecimentos, indicando confiança e colaboração, aspectos importantes para qualquer organização (NERKAR; PARUCHURI, 2005). As redes de conhecimento são, portanto, um aspecto importante do processo de inovação para as organizações (HUGGINS; JOHNSTON, 2010; SAMMARRA; BIGGIERO, 2008).

Com isso, as organizações ao considerarem a construção das redes de conhecimento, passam a ser capazes de realizarem inovações de maneira mais ágil, uma vez que as fontes, fluxos e nós de conhecimentos de suas redes estão expostos de maneira formal. Os modelos adotados pelas organizações podem influenciar de maneira direta essas redes, uma vez que os modelos possuem uma série de variáveis que as influenciam às construções de conhecimentos e por fim, às inovações.

\section{A TERCEIRIZAÇÃO DA PRODUÇÃO COMO MODELO COMPETITIVO: A INOVAÇÃO DE PRODUTOS COM BASE EM CONHECIMENTOS}

As indústrias, com o passar dos anos, buscam reduzir cada vez mais as suas atividades e desperdícios, e com isso, direcionar os seus esforços às atividades que podem proporcionar maior competitividade para os seus produtos. Algumas empresas estão repensando até seu processo de fabricação, uma vez que este processo é visto apenas como uma parte das atividades que envolvem os seus produtos.

0 modelo de terceirização de atividades de produção consiste em uma abordagem moderna e complexa que consiste em um conjunto de ferramentas para eliminar desperdícios de inúmeros fatores (DOLAK,2016). Essa percepção é evidenciada por Andrade e Futado (2005, p.362),

A externalização da manufatura tem sido frequentemente, se não predominantemente, vista como uma ferramenta de redução de custos, em que se ressalta sua origem nos setores tradicionais e em atividades intensivas em mão-de-obra. Entretanto, a estratégia abarca agora muitas tarefas diferentes e deve ser vista como uma poderosa arma competitiva, e não apenas em termos estáticos, visando custos e competição via preço. A externalização pode ser entendida, de fato, como um caminho para as empresas inovativas, "de marca", acelerarem suas estratégias de inovação. Isto acontece principalmente em setores e indústrias dinâmicas, em que o tempo de chegar ao mercado é crucial para aumentar as possibilidades de sucesso e correspondentes recompensas - lucros, reconhecimento de marcas e fatias de mercado. 
Existem inúmero exemplos de empresas que realizam a terceirização de sua produção para outras empresas, talvez o caso mais conhecido seja a Nike. Essa indústria do segmento esportivo possui como foco o desenvolvimento do conceito de novos produtos, a construção de novas estratégias comerciais e de marketing, repassando toda a sua produção de produtos para empresas focadas na produção das suas construções conceituais.

A opção pela adoção da terceirização da produção perpassa por dois diferentes objetivos, sendo o primeiro, motivado pela necessidade de atingir maiores níveis de produtividade e o segundo, devido aos custos de produção. Abreu e Sorj (1994, p.64) definem a primeira opção apontada como a

[...]terceirização da produção motivada pelas necessidades de alcançar níveis de qualidade e produtividade superiores. As inovações tecnológicas e de gestão da produção obtidas ao nível da empresa subcontratante são transferidas para as empresas subcontratadas. 0 segundo caso que pode ser chamado de "terceirização por contingência" significa a externalização da produção como mecanismo de redução de custos de produção. Transferir para o trabalhador os custos de energia, equipamento e espaço e apoiar-se numa força de trabalho sem o ônus da legislação trabalhista são as motivações principais da subcontratação no segundo modelo.

Um dos pontos característicos desse modelo de negócio consiste na descentralização de responsabilidade (KARLSSON; ÅHLSTRÖM, 1996). Nesse sentido, todo o processo de construção de conhecimento torna-se complexo, uma vez que, independente da motivação do processo de terceirização da produção, pode ocasionar a perda total de controle de variáveis relacionadas à produção.

Em contrapartida, conforme mencionado por Andrade e Futado (2005) as organizações ao adotarem esse modelo podem dispender toda as suas energias em processos de inovações, em especial na inovação de produtos. Alguns fatores foram identificados como importantes e capazes de estimular o pensamento criativo no contexto das inovações voltadas para produtos:

- clima de liberdade e abertura organizacional;

- $\quad$ trabalho em equipe;

- $\quad$ uma abordagem sistemática à solução de problemas, e;

- $\quad$ a seleção e uso de um conjunto adequado de ferramentas para geração de ideias (GALANAKIS, 2006; AMABILE, 2008; JUNG; FRANK; CATEN, 2010).

Observa-se que todos os fatores mencionados são importantes variáveis e reforçam a necessidade de construção de conhecimentos voltados para a inovação. Zahra e Covin (1994) mencionam que a inovação pode ser considerada como um fator factual para a sobrevivência e crescimento das organizações, independente de seus segmentos. 
Nesse sentido, Urabe (1988) conceitua inovação como um processo responsável pela criação e implementação de novas ideias responsáveis por resultar em novos produtos, processos ou serviços. Dentre os tipos de inovação de produtos, o mais tradicional é a introdução de um novo bem ou com melhora significativa, e com isso essas inovações podem

[...] utilizar novos conhecimentos ou tecnologias, ou podem basear-se em novos usos ou combinações para conhecimentos ou tecnologias existentes. 0 termo "produto" abrange tanto bens como serviços. As inovações de produto incluem a introdução de novos bens e serviços, e melhoramentos significativos nas características funcionais ou de uso dos bens e serviços existentes (MANUAL, 1997, p.57).

Um estágio importante na inovação de produto são os seus lançamentos, onde $80 \%$ de novos produtos não são bem-sucedidos, o que leva ao desaparecimento em média ao fim do primeiro ano de vida (KOTLER; ARMSTRONG, 2015).

A maneira pela qual a organização modifica a promoção de seus produtos junto ao seu mercado, também pode ser vista como uma inovação, sendo esta inovação baseada em conhecimentos construídos junto ao mercado externo das organizações, afinal, essas ações são direcionadas aos mercados e às necessidades dos consumidores, com o objetivo de aumento de vendas, fixação e fortalecimento da marca e sua imagem, bem como aumentar a sua visibilidade. Com isso, consideramos como inovação de marketing a implementação de um novo método de marketing, desde que possua mudanças significativas em todo o contexto do produto (MANUAL..., 1997, p.59).

Nesse contexto, podemos considerar mudanças substanciais no design ou na concepção de produtos, desde que não alterem suas características funcionais ou de uso. Com isso podemos compreender que se tratam de mudanças na maneira de empacotar/embalar os produtos, independentemente de sua finalidade, em que a embalagem passa a ser determinante na aparência do produto ou mudanças na forma, aparência ou sabor de alimentos ou bebidas, como por exemplo, a introdução de novos aromatizantes em produtos de alimentação para que se possa atingir um novo segmento de consumidores (MERCALDI et al, 2015).

No momento em que as organizações adotam políticas e abordagem de inovações passam a ter uma maior ênfase na "[...] interação entre instituições e observam processos interativos na criação, difusão e aplicação de conhecimentos" (MANUAL..., 1997, p.41). Observe-se que nesse momento as organizações passam a construir verdadeiras redes de conhecimento voltadas para a cooperação, tanto no ambiente interno quanto externo. 
Nessas redes de cooperação, o que antes era desenvolvido em ações isoladas passa a ser realizado por meio de um modelo integrado, alterando o processo individual para um processo coletivo e com isso as ações desenvolvidas podem assumir diversos destinos em suas relações, afinal, podem ser tanto horizontalizadas como verticalizadas (ROTTWELL, 1995).

A empresa pode investir em atividades de criação para desenvolver inovações internamente sozinha ou em parceria com outras empresas - ou pode adotar inovações desenvolvidas por outras empresas ou instituições como parte de um processo de difusão [...] ambas, criação e adoção de inovações, podem envolver 0 aprendizado intensivo, a interação com outros atores ou interações externas mínimas (MANUAL..., 1997, p.44).

Nesse sentido, devemos considerar as fontes e fluxos de conhecimento voltadas para a construção de novos produtos, sendo estes totalmente variáveis de acordo com o tipo de organização e mercados em que atua. Identificar essas fontes e fluxos pode proporcionar ainda mais competitividade para as organizações que buscam ser mais competitivas, em especial para aquelas que abriram mão de ter em sua estrutura a produção de seus produtos.

\section{PROCEDIMENTOS METODOLÓGICOS E UNIVERSO DE PESQUISA}

Para a realização da pesquisa foi utilizado o método ‘Estudo de Caso'. Yin (2001, p.21), menciona que o método estudo de caso "[...] contribui, de forma inigualável, para a compreensão que temos dos fenômenos individuais, organizacionais, sociais e políticos”. Nesse sentido, foi aplicada a triangulação de dados, método este que faz uso simultaneamente de três técnicas.

Dessa maneira foi utilizado o processo de observação direta na organização analisada, a aplicação de questionários e a aplicação de entrevistas. Destaque-se que foi necessário coletar dados e informações em todos os níveis da organização. 0 uso da triangulação propicia uma análise ampliada sobre o fenômeno em questão, obtendo assim resultados mais densos, bem como, confere um maior valor aos dados e análises realizadas.

Gil (2002) e Marconi e Lakatos (2003) destacam a importância da realização do processo de observação direta, afinal, por meio dele identificam-se padrões, ações e indicadores das organizações pesquisadas. Destaque-se que foi realizada uma entrevista estruturada com o diretor da empresa e com isso foi possível validar pontos encontrados na observação direta e no questionário.

Marconi e Lakatos (2003, p.200) reforçam a importância do questionário, apontando este como: "[...] um instrumento de coleta de dados, constituído por uma série ordenada de perguntas, que devem ser respondidas por escrito [...]”. Indo ao encontro de Marconi e Lakatos (2003), Gil (2002) destaque-se que o questionário é um método econômico e rápido para levantamento de informações de pesquisa. 


\subsection{Universo de Pesquisa}

A pesquisa foi realizada na Danilla Foods (DANILLA), indústria de alimentos que exporta seus produtos para vários países, localizada na cidade de Marília, interior do estado de São Paulo. Nesse sentido, a empresa começou a construir sua história em 2002, com a missão de apoiar empresas de Marília e região no segmento de exportação e importação de produtos alimentícios.

Nos últimos doze (12) anos, a empresa vem participando das principais feiras internacionais como ISM Cologne (Alemanha), SIAL (França), Dubai etc., no intuito de se aprimorar e acompanhar as tendências e oportunidades de mercado mundial de doces e confeitos.

Acompanhando tais tendências de mercado, a empresa identificou oportunidades e, em 2010, desenvolveu uma linha de produtos diferenciados, inovadores e com preços competitivos. No âmbito dos produtos desenvolvidos destacam- se os seguintes: Danilla $₫$, Dip Loko $®$, Dantoy $\circledast$, Disco Loko $₫$,

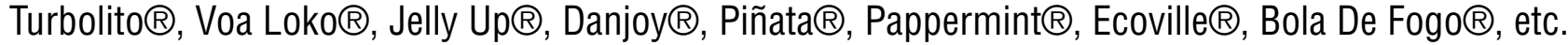
Destaque-se que a empresa está sempre analisando tendências, oportunidades e o mercado e com isto, construindo novos produtos.

Atualmente a DANILLA possui onze (11) sujeitos atuando em cinco áreas básicas (figura 1): comercial, marketing, administrativo, logística e comércio exterior, sendo dirigida por um diretor geral, responsável pelas diretrizes estratégicas da organização. Nesse contexto, a empresa possui um único gestor responsável por coordenar as ações voltadas para o comércio exterior e marketing da empresa.

Figura 1- Organograma da Danilla Foods

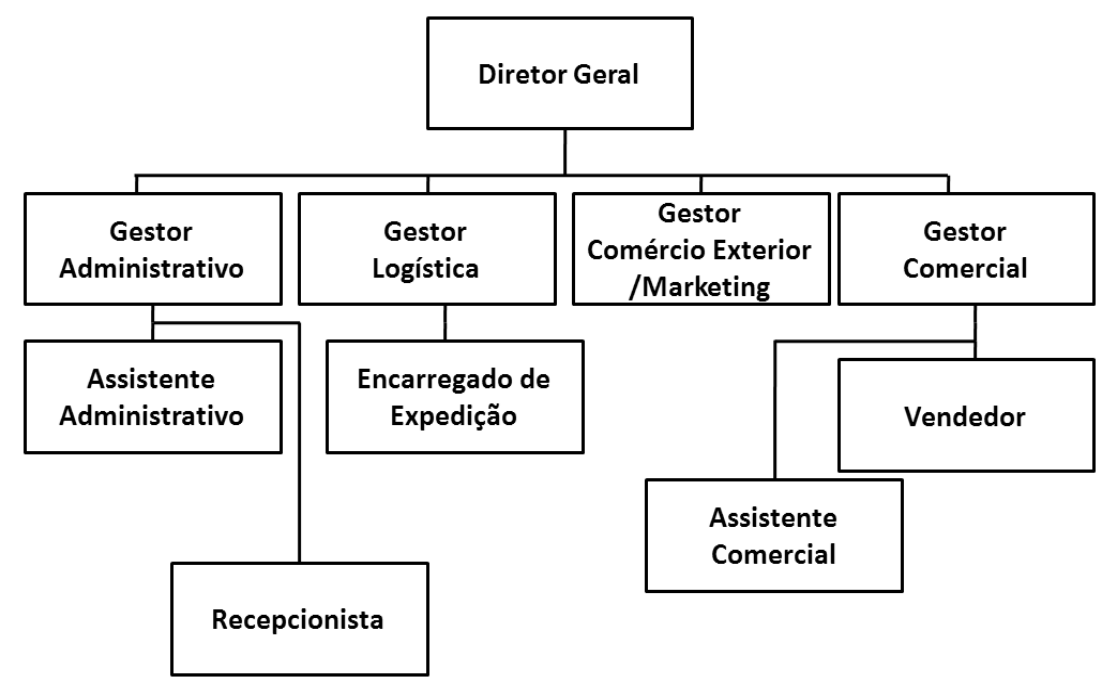

Fonte: Elaborado pelos autores (2019). 
A gestão da área administrativa é realizada por um gestor e dois auxiliares administrativos responsáveis por todos os processos e atividades de contas a receber, contas a pagar, recursos humanos, entre outras. 0 processo de recepção está vinculado à gestão administrativa e é responsável pelo primeiro atendimento da empresa, seja pessoalmente ou por telefone.

Os processos voltados à logística e à expedição são realizados atualmente por um encarregado supervisionado por um sujeito responsável por sua gestão. Cabe a essa área toda a distribuição dos produtos vendidos pela área comercial, a análise da melhor forma de entrega, a análise de fornecedores e outras atividades que estão diretamente ligadas à expedição e à logística do produto.

A área comercial é composta por um sujeito responsável por gerir essas atividades, um vendedor e um assistente. 0 assistente, atualmente, é responsável por propiciar a retaguarda para 0 vendedor e o gestor de vendas; 0 vendedor tem a função de prospectar novos clientes (representantes comerciais) e parceiros (distribuidoras), enquanto o gestor atua no gerenciamento dos processos de vendas, mas principalmente no desenvolvimento de estratégias voltadas para a venda de produtos da DANILLA, por parte das empresas que representam seus produtos.

É possível observar que a organização possui uma estrutura enxuta devido ao modelo de negócio adotado, ou seja, a terceirização da produção. Com esse processo a organização ganha maior dinamicidade, afinal, com todas as áreas integradas em um único espaço. Essa dinâmica proporciona agilidade no processo de construção de conhecimento, inovação, bem como no atendimento das necessidades de mudanças ou absorção de novas diretrizes impostas pelo mercado.

\section{APRESENTAÇÃO DOS DADOS}

Foi realizado o mapeamento dos fluxos, bem como as fontes mais acessadas utilizando-se 0 sociograma. Segundo Jorge e Valentim (2016, p.165) o sociograma é a "[...] técnica que permite a compreensão aprofundada das relações entre os indivíduos de um grupo ou entre grupos”. Ao utilizar essa ferramenta foi possível entender de maneira mais clara quais são os indivíduos mais acessados em vários contextos na DANILLA, além disso, também foi possível compreender como é composta a rede de conhecimento.

Sendo assim, buscou-se compreender junto aos sujeitos da pesquisa a quem recorrem quando necessitam de informações e conhecimentos frente a muitos contextos. Dentro das informações analisadas buscou-se compreender a busca desses sujeitos no contexto interno da organização: 
acesso a informações e conhecimentos de atividades desempenhadas pelo sujeito no ambiente interno e 0 acesso a informações e conhecimentos de atividades diversas no ambiente interno. Observe-se que esses acessos foram somados para dar a real importância de maneira macro de cada função na empresa, no contexto da construção de conhecimento, e com isso, formaram-se nós de conhecimento.

No contexto externo da DANILLA foram analisados: acesso a informações e conhecimentos de atividades desempenhadas pelo sujeito no ambiente externo; acesso a informações e conhecimentos de atividades diversas pelo sujeito no ambiente externo. Além dessas informações mencionadas, também foram totalizados esses dois contextos para compreender os componentes que são considerados no ambiente externo e utilizados na construção de conhecimentos no ambiente interno.

Destaque-se que não houve limitação em relação à quantidade de indicações, e portanto, alguns sujeitos apontaram mais de uma fonte nos questionamentos. Outro ponto que merece atenção consiste na junção de pessoas que executam e ocupam o mesmo cargo, ou seja, os apontamentos desses sujeitos foram somados dentro de suas funções, tornando assim a pesquisa mais formal, construindo a rede dentro do organograma da empresa.

Tabela 1- Total de acesso a informações e conhecimentos no ambiente interno da DANILLA.

\begin{tabular}{|c|c|c|c|c|c|c|c|c|c|c|}
\hline $\begin{array}{l}\text { Quem } \\
\begin{array}{r}\text { Concede } \\
\text { informação }\end{array} \\
\text { requer } \\
\text { informação }\end{array}$ & 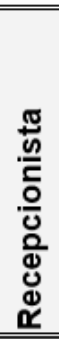 & 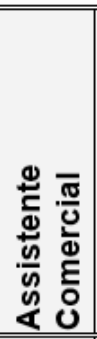 & 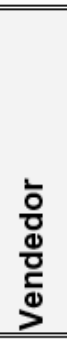 & 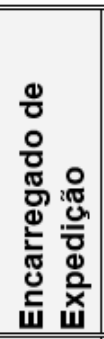 & 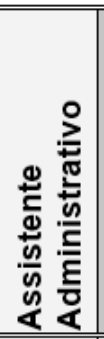 & 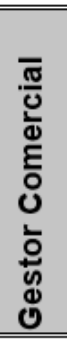 & 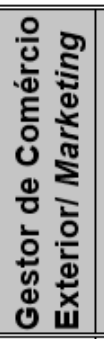 & 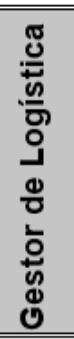 & 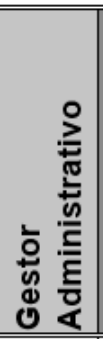 & 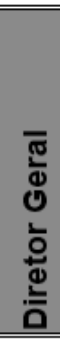 \\
\hline Recepcionista & & & & & & & & 2 & 1 & \\
\hline Assistente Comercial & & & & & & 1 & & & 2 & \\
\hline Vendedor & & 1 & & & 1 & 1 & 1 & 2 & 2 & \\
\hline Encarregado de Expedição & & & & & & 1 & 1 & 2 & 1 & \\
\hline Assistente Administrativo & & & & & & 1 & 1 & 1 & 2 & \\
\hline Gestor Comercial & & 1 & & & & . & & & 1 & \\
\hline $\begin{array}{l}\text { Gestor de Comércio Exterior } \\
\text { I Marketing }\end{array}$ & & & & & & 1 & & & & 1 \\
\hline Gestor de Logística & & & & & & 1 & 1 & & 2 & \\
\hline Gestor Administrativo & & & & & 1 & 1 & & 1 & & 1 \\
\hline Diretor Geral & & & & & & 1 & 1 & 1 & 1 & \\
\hline Total & 0 & 2 & 0 & 0 & 2 & 8 & 5 & 9 & 12 & 2 \\
\hline \begin{tabular}{|l}
$\square$ \\
$\square$ Nível Operacional \\
Nível Tático \\
Nível Estratégico
\end{tabular} & & & & & & & & & & \\
\hline
\end{tabular}

Fonte: Desenvolvido pelos autores (2019). 
É possivel observar na soma dos questionários que abordaram as fontes de informações ou conhecimentos internos ou externos proporcionando uma centralização de acessos no nível tático, mais precisamente no gestor administrativo, sujeito que possui a maior centralidade dos acessos, doze (12), seguido pelo gestor de logística com nove (9) e o gestor comercial com oito (8). Com essa informação é possível verificar que as os sujeitos que realizam as ações fundamentais, no contexto da DANILLA, são mais requisitados em nível de informação e conhecimento, conforme pode ser visualizado na figura 2.

Figura 2 - Sociograma dos acessos às fontes internas da DANILLA.

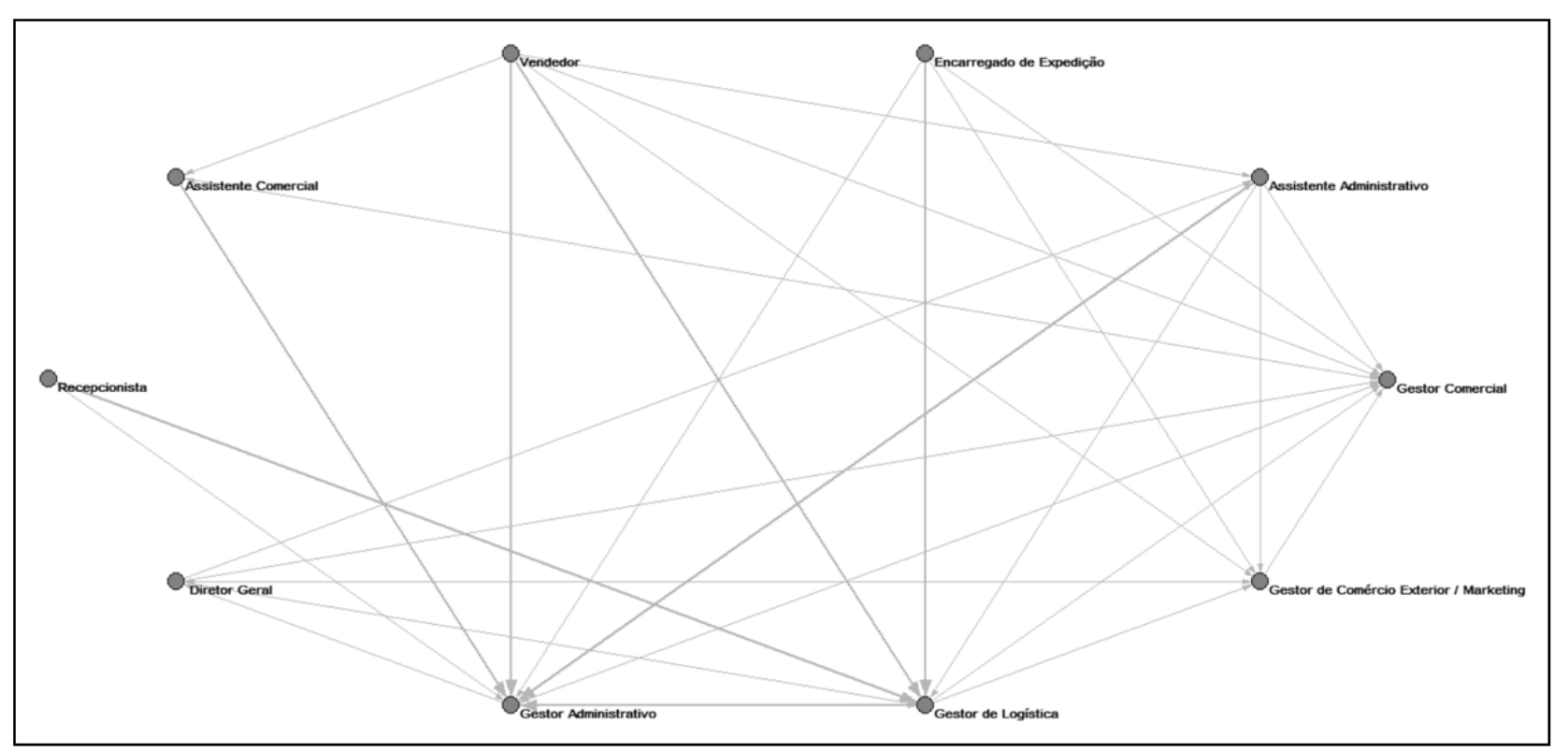

Fonte: Desenvolvido pelos autores (2019).

Ao observarmos a totalização dessas informações e conhecimentos, torna-se importante compreender quais são os sujeitos que são acessados para informações e conhecimentos de atividades desempenhadas no ambiente interno (tabela 2) e os sujeitos que são fontes de informações e conhecimentos de atividades diversas no ambiente externo (tabela 3). Essa análise é importante, pois cada sujeito pode ser fonte de informações em intensidades diferentes de acordo com o contexto das informações e conhecimentos requisitados.

Nesse sentido, observa-se na tabela 2, ou seja, o acesso a informações e conhecimentos de atividades desempenhadas pelo sujeito no ambiente interno, a centralidade de informações no gestor administrativo, com cinco (5) acessos. Outro sujeito que recebeu um número expressivo de acessos foi 0 gestor de logística, com três (3) acessos. Observa-se que o gestor comercial obteve a mesma 
quantidade de acessos que a função de assistente administrativo, ambos com dois (2) acessos, demonstrando assim que no contexto das informações e conhecimentos do ambiente interno estes sujeitos possuem uma intensidade menor de acessos em comparação ao gestor administrativo e 0 gestor de logística.

Tabela 2 - Acesso a informações e conhecimentos de atividades desempenhadas pelo sujeito no ambiente interno.

\begin{tabular}{|c|c|c|c|c|c|c|c|c|c|c|}
\hline $\begin{array}{r}\text { Quem } \\
\text { Concede } \\
\text { informação }\end{array}$ & 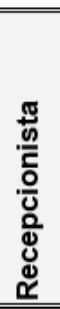 & 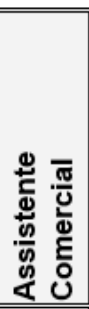 & 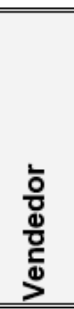 & 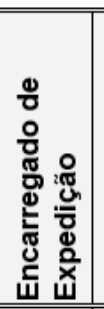 & 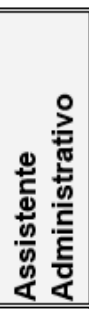 & 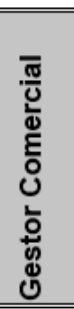 & 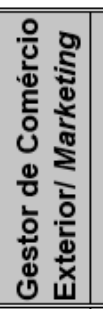 & 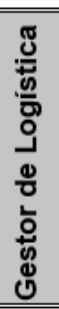 & 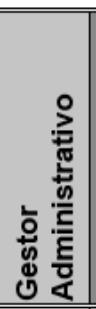 & 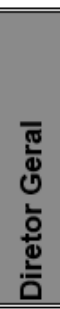 \\
\hline Recepcionista & & & & & & & & 1 & 1 & \\
\hline Assistente Comercial & & & & & & 1 & & & 1 & \\
\hline Vendedor & & 1 & & & 1 & 1 & 1 & 1 & 1 & \\
\hline Encarregado de Expedição & & & & & & & & 1 & & \\
\hline Assistente Administrativo & & & & & & & & & 1 & \\
\hline Gestor Comercial & & 1 & & & & & & & & \\
\hline $\begin{array}{l}\text { Gestor de Comércio Exterior } \\
\text { I Marketing }\end{array}$ & & & & & & & & & & 1 \\
\hline Gestor de Logística & & & & & & & & & 1 & \\
\hline Gestor Administrativo & & & & & 1 & & & & & \\
\hline \multicolumn{11}{|l|}{ Diretor Geral } \\
\hline Total & 0 & 2 & 0 & 0 & 2 & 2 & 1 & 3 & 5 & 1 \\
\hline
\end{tabular}

Fonte: Desenvolvido pelos autores (2019).

Ao considerarmos os sujeitos como fontes de informações e conhecimentos externos o resultado foi bastante diferente e não condiz com a realidade visualizada por meio do roteiro de observação na empresa. A centralidade dos acessos continua no gestor administrativo, ou seja, sete (7) pessoas apontaram que ele é a fonte de informações e conhecimento do ambiente externo, seguido do gestor de logística e do gestor comercial, com seis (6) acessos cada, e finalizando a centralidade dos acessos, 0 gestor de comércio exterior / marketing com quatro (4) acessos.

Foi possível identificar graças ao uso do roteiro de observação que a centralização de acessos não reflete de fato a fonte de conhecimentos e informações do ambiente externo. Tal apontamento ocorre, pois, por mais que os sujeitos apontem o acesso ao gestor administrativo, as informações e 
conhecimentos sobre o ambiente externo são provenientes dos gestores de comércio exterior/marketing, comercial e de logística, sendo o gestor administrativo apenas o mediador dessas informações no contexto da organização.

Tabela 3 - Acesso a informações e conhecimentos de atividades desempenhadas pelo sujeito no ambiente externo.

\begin{tabular}{|c|c|c|c|c|c|c|c|c|c|c|}
\hline $\begin{array}{r}\text { Quem } \\
\begin{array}{r}\text { Concede } \\
\text { informação }\end{array} \\
\text { Quem } \\
\text { requer } \\
\text { informação }\end{array}$ & 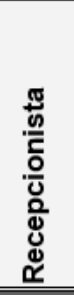 & 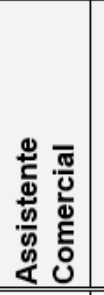 & 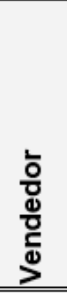 & 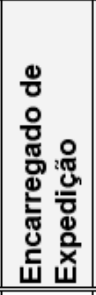 & 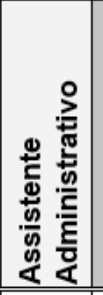 & 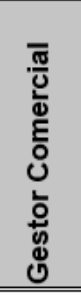 & 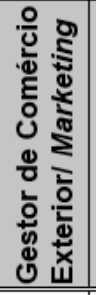 & 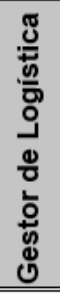 & 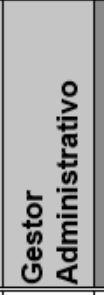 & 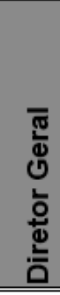 \\
\hline Recepcionista & & & & & & & & 1 & & \\
\hline Assistente Comercial & & & & & & & & & 1 & \\
\hline Vendedor & & & & & & & & 1 & 1 & \\
\hline Encarregado de Expedição & & & & & & 1 & 1 & 1 & 1 & \\
\hline Assistente Administrativo & & & & & & 1 & 1 & 1 & 1 & \\
\hline Gestor Comercial & & & & & & & & & 1 & \\
\hline $\begin{array}{l}\text { Gestor de Comércio Exterior } \\
\text { I Marketing }\end{array}$ & & & & & & 1 & & & & \\
\hline Gestor de Logística & & & & & & 1 & 1 & & 1 & \\
\hline Gestor Administrativo & & & & & & 1 & & 1 & . & 1 \\
\hline Diretor Geral & & & & & & 1 & 1 & 1 & 1 & \\
\hline Total & 0 & 0 & 0 & 0 & 0 & 6 & 4 & 6 & 7 & 1 \\
\hline
\end{tabular}

Fonte: Desenvolvido pelos autores (2019).

Os sujeitos também foram questionados quanto ao acesso de fontes externas, sendo estas apresentadas na tabela 4. Observa-se que a totalização dos resultados que tratam do acesso a informações e conhecimentos de atividades diversas pelo sujeito no ambiente externo e 0 acesso a informações e conhecimentos de atividades desempenhadas pelo sujeito no ambiente externo obteve uma centralização de resultados em 4 (quatro) fontes.

Destacamos que a não procura por fonte externa, caracterizada pela pesquisa como 'ninguém', é mencionada por sete (7) diferentes pessoas. Essa situação ocorre devido à falta de percepção quanto à caracterização de fontes externas, uma vez que ao realizar a observação direta, alinhada com a entrevista realizada com o diretor geral da empresa, ficou evidente que existem inúmeras fontes externas que são acessadas o tempo todo, principalmente pelos gestores da empresa. 
Nesse sentido, considerando os apontamentos realizados pelos sujeitos quanto às fontes de informações e conhecimentos do ambiente externo, seis (6) apontamentos foram realizados para a transportadora e representantes, sendo estas importantes fontes responsáveis por dar consistência às atividades da empresa. Esse apontamento consiste no modelo de indústria encontrada na DANILLA, afinal, toda sua estrutura de controle consiste na construção de conceitos e produtos, bem como na logística e venda de seus produtos.

Tabela 4 - Total de acesso a informações e conhecimentos pelo sujeito no ambiente externo

\begin{tabular}{|c|c|c|c|c|c|c|c|c|c|c|c|c|c|c|}
\hline $\begin{array}{l}\text { Fonte de } \\
\text { Informação e } \\
\text { conhecimento }\end{array}$ & 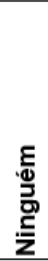 & 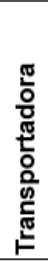 & $\underset{\tilde{x}}{\mathrm{~T}}$ & 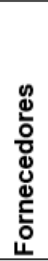 & 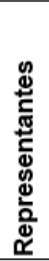 & 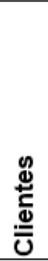 & 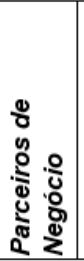 & 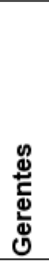 & 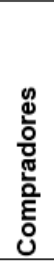 & 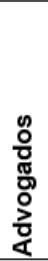 & 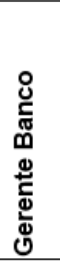 & $\begin{array}{l}\frac{0}{0} \\
\frac{\pi}{0} \\
\frac{0}{0} \\
\frac{0}{50} \\
0 \\
0 \\
0\end{array}$ & త్ర & 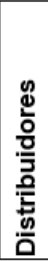 \\
\hline Recepcionista & 2 & & & & & & & & & & & & & \\
\hline Assistente Comercial & & & & 1 & 2 & 1 & & & & & & & & \\
\hline Vendedor & & & & & & & & 1 & 1 & & & & & 1 \\
\hline Encarregado de Expedição & 1 & 4 & & & & & & & & & & & & \\
\hline Assistente Administrativo & & & 1 & 2 & 2 & 2 & & & & 1 & 1 & & & \\
\hline Gestor Comercial & & & & & 1 & & & & & & & & 1 & 1 \\
\hline $\begin{array}{l}\text { Gestor de Comércio Exterior/ } \\
\text { Marketing }\end{array}$ & 2 & & & & & & & & & & & & & \\
\hline Gestor de Logística & & 2 & & & & & & & & & & & & \\
\hline Gestor Administrativo & & & 1 & & 1 & 1 & 1 & & & 1 & & 1 & 1 & \\
\hline Diretor Geral & 2 & & & & & & & & & & & & & \\
\hline Total & 7 & 6 & 2 & 3 & 6 & 5 & 1 & 1 & 1 & 2 & 1 & 1 & 2 & 2 \\
\hline
\end{tabular}

Nível Operacional

Nivel Tático

Nível Estratégico

Fonte: Desenvolvido pelos autores (2019).

Outra fonte que chamou atenção na pesquisa consiste em não ter uma expressiva quantidade de acesso a clientes, porém, ao realizar a observação direta essa condição consiste no modelo de negócio da empresa, uma vez que a área comercial e de vendas é caracterizada por possuir representantes que realizam as atividades de venda e comercial, logo, os acessos aos clientes são realizados via representantes. As demais fontes acessadas possuem uma frequência menor, uma vez que estão relacionadas a atividades meio da empresa, e isso, torna seu acesso menos denso.

Ao considerarmos o resultado sem a soma, temos as duas categorias relacionadas ao ambiente externo já mencionado, sendo assim, torna-se importante realizar a análise desses acessos para uma compreensão mais aprofundada. Nesse sentido, o acesso a informações e conhecimentos de atividades diversas pelo sujeito no ambiente externo foi tratado de maneira individual. 
Nesse sentido, conforme pode ser observado na tabela 5, quatro (4) sujeitos apontaram não recorrerem a ninguém nesse processo. A mesma quantidade de pessoas, ou seja, quatro (4), apontou que acessa os representantes como fonte de informações e conhecimento externo para atividades diversas. Completando os acessos relevantes encontramos os clientes com dois (2) acessos.

Tabela 5 - Acesso a informações e conhecimentos de atividades diversas pelo sujeito no ambiente externo.

\begin{tabular}{|c|c|c|c|c|c|c|c|c|c|}
\hline $\begin{array}{r}\text { Fonte de } \\
\text { Informação e } \\
\text { conhecimento }\end{array}$ & 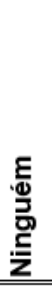 & 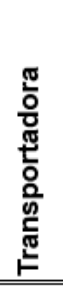 & $\underset{\underline{\underline{\mu}}}{\underline{T}}$ & 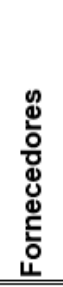 & 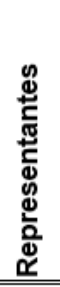 & 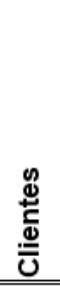 & 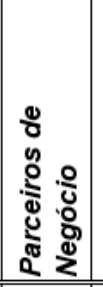 & 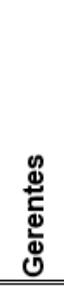 & 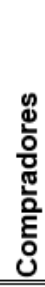 \\
\hline Recepcionista & 1 & & & & & & & & \\
\hline Assistente Comercial & & & & & 1 & & & & \\
\hline Vendedor & & & & & & & & 1 & 1 \\
\hline Encarregado de Expedição & 1 & & & & & & & & \\
\hline Assistente Administrativo & & & & 1 & 1 & 1 & & & \\
\hline Gestor Comercial & & & & & 1 & & & & \\
\hline $\begin{array}{l}\text { Gestor de Comércio Exterior/ } \\
\text { Marketing }\end{array}$ & 1 & & & & & & & & \\
\hline Gestor de Logística & & 1 & & & & & & & \\
\hline Gestor Administrativo & & & & & 1 & 1 & 1 & & \\
\hline Diretor Geral & 1 & & & & & & & & \\
\hline Total & 4 & 1 & 0 & 1 & 4 & 2 & 1 & 1 & 1 \\
\hline
\end{tabular}

Fonte: Desenvolvido pelos autores (2019).

Os sujeitos que compõem a empresa, ao serem questionados quanto ao acesso a informações e conhecimentos de atividades desempenhadas por eles no ambiente externo apresentaram uma pulverização nos acessos, conforme pode ser visualizado na tabela 6 . Assim como no primeiro agrupamento, a não procura de fontes externas recebeu três (3) apontamentos, enquanto que, com exceção do gerente de banco e a contabilidade, que receberam um apontamento, as demais fontes foram apontadas por pelo menos dois sujeitos. Isso evidencia que os acessos externos para a realização das atividades estão totalmente relacionados às atividades dos sujeitos e com isso esses acessos acabam sendo realizados dentro dos interesses de atividades. 
Tabela 6 - Acesso a informações e conhecimentos de atividades desempenhadas pelo sujeito no ambiente externo

\begin{tabular}{|c|c|c|c|c|c|c|c|c|c|c|c|}
\hline $\begin{array}{l}\text { Qonte de } \\
\text { Quem } \\
\text { requer } \\
\text { informação }\end{array}$ & 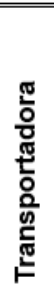 & 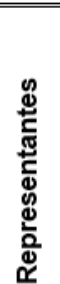 & 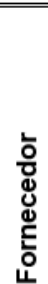 & 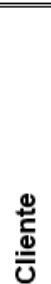 & $\underset{\boldsymbol{I}}{\boldsymbol{I}}$ & 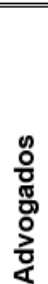 & 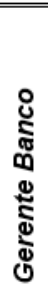 & 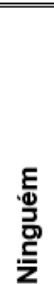 & 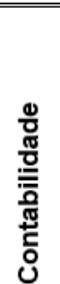 & త్ర & 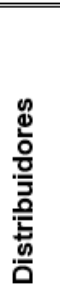 \\
\hline Recepcionista & & & & & & & & 1 & & & \\
\hline Assistente Comercial & & 1 & 1 & 1 & & & & & & & \\
\hline Vendedor & & & & & & & & & & & 1 \\
\hline Encarregado de Expedição & 1 & & & & & & & & & & \\
\hline Assistente Administrativo & & 1 & 1 & 1 & 1 & 1 & 1 & & & & \\
\hline Gestor Comercial & & & & & & & & & & 1 & 1 \\
\hline $\begin{array}{l}\text { Gestor de Comércio Exterior/ } \\
\text { Marketing }\end{array}$ & & & & & & & & 1 & & & \\
\hline Gestor de Logística & 1 & & & & & & & & & & \\
\hline Gestor Administrativo & & & & & & 1 & & & 1 & 1 & \\
\hline Diretor Geral & & & & & & & & 1 & & & \\
\hline Total & 2 & 2 & 2 & 2 & 1 & 2 & 1 & 3 & 1 & 2 & 2 \\
\hline
\end{tabular}

Fonte: Desenvolvido pelos autores (2019).

Ao alinhar os dados colhidos no roteiro de observação, questionário fechado e entrevista realizada com o diretor da empresa, foi possível compreender que a DANILLA considera como muito importante a construção de novos conhecimentos e que estes são utilizados nas inovações no contexto dos produtos. Todavia, houve a percepção de que estas construções e inovações ocorrem de maneira não estruturada e logo, observou-se a falta de percepção dos sujeitos sobre as fontes de informações e de conhecimento nesse processo.

\section{CONSIDERAÇÕES PARCIAIS}

Por meio da realização da presente pesquisa, foi possível evidenciar quais são as fontes informacionais e de conhecimento mais acessadas o que consequentemente resultou nos fluxos mais relevantes para os sujeitos que compõem a Danilla Foods (DANILLA). Ao analisar as fontes e fluxos existentes na empresa, observou-se a necessidade de que o conhecimento seja tratado de maneira estruturada, e com isso, potencializar as inovações, em especial as voltadas para o desenvolvimento de novos produtos, estratégias comerciais e marketing, além de estratégias de logísticas, pontos fundamentais no atual modelo de negócio da DANILLA. 
É importante reforçar que ao considerar o ambiente interno, os sujeitos mais requisitados pelos colaboradores da DANILLA são os sujeitos responsáveis por toda a articulação do coração da empresa, no caso a área de comercial e vendas, administrativa e logística. Outro ponto que merece atenção está na centralização de acessos ao gestor administrativo, sendo este muitas vezes utilizado apenas como ponto para 0 acesso às informações necessárias.

Em contrapartida, não houve a compreensão da importância das fontes do ambiente externo, uma vez que as mesmas são acessadas, porém os sujeitos não possuem percepção de valor dessas fontes, afinal, muitas delas não foram nem ao menos mencionadas.

Essas percepções apontam a fragilidade, bem como uma possível dificuldade da empresa na implementação de atividades e processos que atuam com as informações e conhecimentos de maneira estruturada. A fragilidade é apontada pela pesquisa ao evidenciar a importância do mapeamento da rede de conhecimento frente à falta de percepção desses sujeitos.

Afinal, a rede de conhecimento construída pode ser considerada como a estrutura primária que sustenta as atividades de implementação e realização dos processos de Gestão da Informação e do Conhecimento. Destaque-se que, nos fluxos informacionais da empresa, trafegam um número ilimitado de informações, sendo estes fluxos muitas vezes construídos e eliminados de maneira dinâmica, ou seja, de acordo com situações pontuais apresentadas pela empresa.

Um exemplo dessa situação é a construção de um novo produto e/ou o lançamento de uma nova estratégia de marketing, nesse momento acessam-se fontes informacionais e de conhecimentos, construindo fluxos dinâmicos, que são utilizados e descartados após o uso. Isso ocorre, pois, a frequência dessa atividade é sazonal, afinal, são respeitados o ciclo de vida do produto ou estratégia de marketing construída.

Foi possível identificar que muitas informações e conhecimentos que trafegam nos fluxos não são registradas em nenhum suporte, ou seja, dificultando muitas vezes a construção de novos conhecimentos. Também foi possível perceber que a DANILLA realiza de maneira não estruturada várias atividades que remetem à Gestão do Conhecimento e Informação, contudo, evidencia-se a falta de um conjunto metodológico adequado e estruturado, influindo assim, no uso da rede de conhecimento enquanto ferramenta estratégica para a construção de conhecimento voltado para a inovação de produtos.

Nesse sentido, recomenda-se como parâmetro para um melhor aproveitamento das informações e conhecimentos contidos na rede de conhecimento da DANILLA, a adoção de tecnologias de informação 
e comunicação (TICs) que propiciem o mapeamento e centralização das informações relevantes em uma única base de dados. Alinhada à adoção de TICs, recomenda-se a inserção de um profissional da informação na estrutura da empresa, afinal, esse profissional pode ser um componente estratégico em atividades que envolvam informações e conhecimento, desde a construção da cultura voltada para estes componentes, até mesmo o uso estruturado. Com isso, o acesso, armazenamento, tratamento, organização, gestão e disseminação das informações para uso nas atividades centrais da empresa podem se tornar mais eficientes, em especial nos processos de inovação.

Recomenda-se a necessidade dos colaboradores de todos os níveis da empresa desenvolverem competência em informação e com isso adquirirem uma melhor percepção da importância da informação e do conhecimento enquanto recursos balizadores de inovação da empresa. Considera-se importante o desenvolvimento de outras pesquisas no âmbito da Ciência da Informação, enfocando esse cenário extremamente complexo, ou seja, indústrias que terceirizam as suas produções (e possuem a inovação como base de suas atividades, bem como aprofundar-se em outros elementos que não foram alvo desta pesquisa.

\section{REFERÊNCIAS}

ABREU, A.; SORJ, B. Subcontratação e trabalho a domicílio. In: MARTINS, H. H. T. S.; RAMALHO, J. R. (Org.) Terceirização: diversidade e negociação no mundo do trabalho. São Paulo: Hucitec, CEDI/ NETS, 1994.

AL-HASHEM, A; SHAQRAH, A. Social knowledge network as an enabling factor for organizational learning. Journal of Theoretical and Applied Information Technology, v. 40 n. 1, p. 1-8, 2012. Disponível em: http://www.jatit.org/volumes/Vol40N01/1Vol40No1.pdf . Acesso em: 03 dez. 2019.

AMABILE, T. M. Creativity and the role of the leader. Harvard Business Review, v.86, n. 10, 2008. Disponível em: https://hbr.org/2008/10/creativity-and-the-role-of-the-leader. Acesso em: $11 \mathrm{dec}$. 2019.

CAVALCANTE, L. F. B.; VALENTIM, M. L. P. Comportamento informacional em ambientes empresariais. In: VALENTIM, M. L. P. (Org.). Gestão da informação e do conhecimento no âmbito da Ciência da Informação. São Paulo: Polis: Cultura Acadêmica, 2008. 272p; p.117-128.

DOLAK, R. Creating a Knowledge Base to Support the Concept of Lean Administration Using Expert System NEST. In International Conference on Computational Collective Intelligence, 2016. Disponível em: https://link.springer.com/chapter/10.1007/978-3-319-45243-2_26 . Acesso em: 12 dec. 2019.

DONG, J. Q.; YANG, C. H. Information technology and organizational learning in knowledge alliances and networks: evidence from US pharmaceutical industry. Information \& Management $v$. 
52 n. 1, p. 111-122, 2015. Disponível em: https://www.sciencedirect.com/science/article/abs/pii/ S0378720614001347. Acesso em: 13 nov. 2019.

GALANAKIS, K. Innovation Process. Make sense using system thinking. Technovation, v.26, n. 1, 2006. Disponível em: https://doi.org/10.1016/j.technovation.2005.07.002 . Acesso em: 05 dec. 2019.

GEBAUER, H.; WORCH, H.; TRUFFER, B. Absorptive capacity, learning processes and combinative capabilities as determinants of strategic innovation. European Management Journal, v. 30 n. 1, p. 5773, 2015. Disponível em: https://www.sciencedirect.com/science/article/abs/pii/S0263237311000740. Acesso em: 5 nov. 2019.

GIL, A. C. Métodos e técnicas da pesquisa social. 6.ed. São Paulo: Atlas, 2008.

KARLSSON, C.; AHLSTRÖM P. Assessing changes towards lean production. International Journal of Operations and Production Management, v. 16, n. 2, 1996. Disponível em: https://www.emerald. com/insight/content/doi/10.1108/01443579610109820/full/html. Acesso em: 12 dec. 2019.

KOTLER P.; ARMSTRONG G. Princípios de Marketing.15. ed. São Paulo: Pearson Education do Brasil, 2015.

JORGE, C. F. B. Análise de fatores críticos na gestão do conhecimento e no processo de inteligência em organizações complexas. 2017. 511f. Tese (Doutorado em Ciência da Informação) - Faculdade de Filosofia e Ciências, Universidade Estadual Paulista, Marília, 2017. Disponível em: https://repositorio.unesp.br/handle/11449/152376. Acesso em : 26 de mai. 2020.

JORGE, C. F. B.; VALENTIM, M. L. P. A importância do mapeamento das redes de conhecimento para a gestão da informação e do conhecimento em ambientes esportivos: um estudo de caso no Marília Atlético. Perspectivas em Ciência da Informação, [S.I.], v. 21, n. 1, p. 152-172, 2016. Disponível em: http://portaldeperiodicos.eci.ufmg.br/index.php/pci/article/view/2533. Acesso em: 03 fev. 2020.

JUNG, C. F.; CATEN, C. S. T.; RIBEIRO, J. L. D. Innovation Process. Make sense using system thinking. Technovation, v.7, n. 2, 2010. Disponível em: https://bjopm.emnuvens.com.br/bjopm/ article/view/V7N2A8 . Acesso em: 05 dec. 2019.

LANE, P. J.; KOKA, B. R.; PATHAK, S. The reification of absorptive capacity: A critical review and rejuvenation of the construct. Academy of Management Review, v. 31 n. 4, p. 833-863, 2006. Disponível em: https://journals.aom.org/doi/abs/10.5465/AMR.2006.22527456. Acesso em: 3 nov. 2019.

MANUAL de Oslo: diretrizes para coleta e interpretação de dados sobre inovação. 3.ed. [S.L.]: OECD; FINEP, 1997. 184p.

MARCONI, M.A.; LAKATOS, E.M. Técnicas de pesquisa: planejamento e execução de pesquisas, amostragens e técnicas de pesquisa, elaboração, análise e interpretação dos dados. São Paulo: Atlas, 2006.

MAYR, A et al. Lean 4.0-A conceptual conjunction of lean management and Industry 4.0. Procedia CIRP. 2018. Disponível em: https://doi.org/10.1016/j.procir.2018.03.292. Acesso em: 02 dec. 2019. 
NAUDÉ, P. et al. Exploiting the B2B knowledge network: New perspectives and core concepts. Industrial Marketing Management, v. 38, n. 5, p. 493-494, 2009. Disponível em: https:// doi.org/10.1016/j.indmarman.2009.02.005. Acesso em: 16 dec. 2019.

MERCALDI, Marlon. et al. Uma visão conceitual da inovação no design brasileiro. In: Fourth International Conference On Design, Engineering, Management For Innovation, 2015, Florianópolis. Anais... Florianópolis: Universidade Estadual de Santa Catarina, 2015. p. 45-55. Disponível em: https://www.academia.edu/17459831/UMA_VIS\%C3\%830_CONCEITUAL_DA_ INOVA\%C3\%87\%C3\%830_NO_DESIGN_BRASILEIRO . Acesso em: 26 mai. 2020.

MORAES, C. R. B. de; FADEL, B. Ambiência organizacional, gestão da informação e tecnologia. In: VALENTIM, M. L.P. (Org.). Informação, conhecimento e inteligência organizacional. 2.ed. Marília: FUNDEPE Editora, 2007. 278p.; p.99-114

NERKAR, A.; PARUCHURI, S. Evolution of R\&D Capabilities: The Role of Knowledge Networks Within a Firm. Management Science, v. 51, n. 1, p. 771-785, 2005. Disponível em: https://doi.org/10.1287/ mnsc.1040.0354. Acesso em: 19 nov. 2019.

HANSEN, M. T.; MORS, M. L.; LØVÅS, B. Knowledge Sharing in Organizations: Multiple Networks, Multiple Phases. The Academy of Management Journal, v. 48, n. 1, p. 776-793, 2005. Disponível em: https://doi.org/10.5465/amj.2005.18803922 . Acesso em: 19 nov. 2019.

HUGGINS, R.; JOHNSTON, A. Knowledge flow and inter-firm networks: The influence of network resources, spatial proximity and firm size. Entrepreneurship \& regional development, v. 22, n. 5, p. 776-793, 2010. Disponível em: https://doi.org/10.1080/08985620903171350. Acesso em: 24 nov. 2019.

ROTTWELL, R. Industrial innovation: success, strategy, trends. In: DODGSON, M.; ROTTWELL, R. The handbook of industrial innovation. Cheltenham: Edward Elgar, 1995.R. The handbook of industrial innovation. Cheltenham: Edward Elgar, 1995.

SAMMARRA, A; BIGGIERO, L. Heterogeneity and specificity of Inter-Firm knowledge flows in innovation networks. Journal of management studies, v. 45, n. 4, p. 800-829, 2008. Disponível em: https://doi.org/10.1111/j.1467-6486.2008.00770.x .Acesso em: 11 dec. 2019.

SEDIGHI, M. et al. Multi-level knowledge sharing: the role of perceived benefits in different visibility levels of knowledge exchange. Journal of Knowledge Management, v. 22, n. 6, p. 1264-1287, 2018. Disponível em: < https://doi.org/ 10.1108/JKM-09-2016-0398>. Acesso em: 10 dec. 2019.

THÉBAUD-MONY,A.; DRUCK, G. Terceirização: a erosão dos direitos dos trabalhadores na França e no Brasil. In: DRUCK, G.; FRANCO, T. A perda da razão social do trabalho: terceirização e precarização. São Paulo: Boitempo Editorial, 2007.

URABE, K. Innovation and the Japanese management system. In K. URABE; J. CHILD; T. KAGONO (Org.), Innovation and management international comparisons. Berlin: Walter de Gruyter, 1988.

VALENTIM, M.L.P. Inteligência competitiva em organizações: dado, informação e conhecimento. DataGramaZero, Rio de Janeiro, v.3, n.4, 2002. Disponível em: https://www.brapci.inf.br/_ repositorio/2010/01/pdf_f589d25523_0007468.pdf. Acesso em: 15 jan. 2012. 
XU, L.; LI, J.; ZENG. How does knowledge network affect a firm's explorative innovation? The contingent role of R\&D collaborations. Technology Analysis \& Strategic Management, v. 29, n. 9, p. 973-987, 2017. Disponível em: https://doi.org/10.1080/09537325.2016.1260105 . Acesso em: 16 dec. 2019.

YIN, R. K. Estudo de caso: planejamento e métodos. 2.ed. São Paulo: Bookman, 2003.

ZAHRA, S.A.; COVIN, J.G. The financial implications of fit between competitive strategy and innovation types and sources. The Journal of High Technology Management Research, v.5 n.2, pp. 183-211, 1994. Disponível em: < https://www.sciencedirect.com/science/article/abs/pii/1047831094900027>. Acesso 26 mai. 2020. 